\title{
Africa and MENA Region (2018)
}

\author{
Nicholas Wasonga Orago*
}

\section{Introduction}

Africa and MENA regions continue to face natural hazard and extreme weather challenges that impact adversely on lives, livelihoods and developmental potentials. Hazard-related disasters include floods, droughts, pest/disease outbreaks, earthquakes, land/mud slides and cyclones/storms. Effective legal, policy and institutional frameworks on disaster risk reduction and management $(\mathrm{DRR} / \mathrm{M})$ are required to respond to these challenges in order to enhance multi-hazard resilience. This correspondence details updates of the legal and institutional frameworks in these regions in 2018.

\section{Disaster Law at the Regional Level in Africa and the African Union}

In Africa, the African Union (AU) is the body mandated to develop and ensure implementation of legal and policy frameworks on DRR/M. ${ }^{1}$ The main regional legal instrument is the Africa Regional DRR Strategy 2004. ${ }^{2}$ The Strategy aims to enhance integration of DRR/M and sustainable development by increasing political commitment; improving identification and assessment of risks; increasing knowledge and awareness; improving institutional and governance frameworks; and ensuring integration of $\mathrm{DRR} / \mathrm{M}$ in emergency response, recovery and rehabilitation. ${ }^{3}$ Its second Programme of Action (POA 2015-2030), adopted in 2016 on the basis of the Sendai Framework, guides Africa's 2018 DRR/M and response activities. ${ }^{4}$ The African Union Commission, especially the Department of Rural Economy and Agriculture (DREA), guides the development and implementation of DRR/M legal and policy frameworks. DREA has the mandate to coordinate efforts aimed at managing desertification

* Llb (Nairobi) Llm (Pretoria) Lld (Western Cape); Irish Research Council and Marie Skłodowska Curie Actions Co-Fund CAROLINE Research Fellow (IFRC/UCC) under MSCA Grant No. 713279 .

1 Constitutive Act of the AU, preamble paras. 5-11, articles 3-4, 9(1)(g) and 13(1)(e).

2 AU, 'Africa Regional Strategy for Disaster Risk Reduction' (July 2004).

3 Ibid., 2 and 9 .

4 AU, 'Programme of Action for the Implementation of the Sendai Framework for Disaster Risk Reduction 2015-2030 in Africa' (November 2016). 
and drought and initiating research on climate change, water and sanitation management. ${ }^{5}$ It has a DRR Unit to enhance regional coordination of $D R R / M$ programmes. ${ }^{6}$

The DRR Unit, with ISDR, coordinates the Regional DRR Platform aimed at enhancing coordinated action in implementing the DRR Strategy and its POAs. $^{7}$ So far, the Platform has been held seven times, with its 7 th Session being a Joint Session on DRR/M with the League of Arab States from 9-13 October 2018 in Tunisia. ${ }^{8}$ It resulted in the Tunis Declaration on DRR of the Sixth High Level Meeting on DRR, which adopted a Monitoring and Reporting Framework for the DRR POA 2015-2030 to generate data for biennial reporting on DRR/M in Africa; called on states and stakeholders to develop risk-informed, holistic and inclusive DRR/M programmes; called on states to ensure national budgetary allocation for $\mathrm{DRR} / \mathrm{M}$; and also called on states to commit to the integration of DRR/M, CCA and sustainable development in legal, policy and programmatic frameworks. ${ }^{9}$ In further efforts to generate data for DRR/M at the regional level, ISDR in 2018 commissioned probabilistic risk profiles of 16 African countries with the aim of using these profiles to transform risks into national DRR/M policies and practices. ${ }^{10}$

The DRR Unit and ISDR are also the co-conveners of the Africa Working Group on Disaster Risk Reduction (AWGDRR), whose role includes the facilitation of mainstreaming and integration of DRR/M in all phases of sustainable development in Africa and the provision of technical support to the regional/ sub-regional DRR/M institutions. ${ }^{11}$ In its 13th Session held in Cameroon from 4-5 September 2018, it deliberated on the following priority concerns: developing an operation plan for the implementation of the DRR POA 2015-2030;

African Union Commission and New Zealand Crown, AU Handbook 2018 (AU Commission and New Zealand Ministry of Foreign Affairs and Trade/Manatū Aorere 2018) 95. AUC, ISDR, WB \& GFDRR Report, 'Building disaster resilience to natural hazards in SubSaharan African regions, countries and communities' (October 2018) 4.

African Union Commission, 'Extended Programme of Action for the Implementation of the Africa Regional Strategy for Disaster Risk Reduction (2006-2015)', available at <http:// www.droughtmanagement.info/literature/UNISDR_africa_regional_strategy_disaster_ risk_reduction_2011.pdf> last accessed (as any subsequent URL) on 27 June 2019, 4; African Union Commission, 'Programme of Action for the Implementation of the Sendai Framework for Disaster Risk Reduction 2015-2030 in Africa' (October 2016) AWg 9 Discussion Draft, 11.

8 UN-ISDR Bulletin, 'The Africa-Arab Platform on Disaster Risk Reduction: 9-13 October 2018' (16 October 2018).

AU 6th Ministerial Meeting on DRR, 'Tunis Declaration on accelerating the implementation of the Sendai Framework for Disaster Risk Reduction 2015-2030 and the Africa Regional Strategy for Disaster Risk Reduction' (13 October 2018).

UNISDR, '2018 Annual Report' (February 2019) 43.

AU Programme of Action 2015-2030 (n. 7) 11. 
enhancing integration and coherence between DRR/M, CCA and sustainable development, especially in National Climate Change Adaptation Plans (NAPs); improving monitoring and reporting processes for the Sendai Framework targets; enhancing collaboration with science and technology community on DRR/M through the establishment of an African Science and Technology Advisory Group; and the development of disaster loss databases and risk profiles. ${ }^{12}$

Further, AUC's Department of Political Affairs, especially its Humanitarian Affairs, Refugees and Internally Displaced Persons (HARDP) Division has a mandate of providing durable solutions to humanitarian crises in the context of humanitarian response and relief, including in disasters. ${ }^{13}$ In 2018, HARDP, in the context of AU Humanitarian Policy Framework and the Common Africa Position of Humanitarian Effectiveness and in collaboration with the IFRC, commenced the process of elaborating a Model Act on Facilitating and Regulating International Disaster Relief and Initial Recovery Assistance so as to enhance AU's procedures for managing international disaster assistance. ${ }^{14}$ HARDP also furthered regional discussions for the creation of the African Humanitarian Agency (AfHA) dedicated to responding to humanitarian situations in Africa, including disaster situations..$^{15}$ If set up and adequately funded, AfHA - in collaboration with the AU Peace and Security Framework ${ }^{16}$ - have the potential to enhance disaster prevention, response and recovery/rehabilitation in Africa. Funding is key to this, and the Africa Risk Capacity has been created to enhance disaster financing, risk pooling and disaster insurance in Africa. ${ }^{17}$ By 2018, the ARC Limited had underwritten over US $\$ 400$ million of disaster risks, received US $\$ 52$ million as premium payments from African States and paid out over US $\$ 34$ million to four African countries (Malawi, Mauritania, Niger and Senegal) in drought support. ${ }^{18}$ In 2018, ARC also engaged

12 AUC and ISDR, 'Concept Note: 13th Session of the Africa Working Group on DRR' (4-5 September 2018).

13 AU Handbook 2018 (n. 5) 93-94.

14 Maria Martinez, 'International Disaster Response Law: A Key Pillar of the AU Humanitarian Policy Framework' (10 July 2018), available at <https://media.ifrc.org/ifrc/2018/07/10/ international-disaster-response-law-key-pillar-african-union-humanitarian-policy -framework/>.

15 AU, 'Press Statement of the 762nd PSC meeting on 'Effective Take-off of the AU Humanitarian Agency (AUHA): Addressing the Impact of Terrorism and Armed conflicts on Africa's Social Fabric" (20 April 2018).

16 AU Handbook 2018 (n. 5) 64; AU, 'Protocol Relating to the Establishment of the Peace and Security Council of the African Union' (2002), arts. 2(1), 6(f), 7(1)(p), 13(3)(f) \& 15.

17 ARC, 'Transforming Disaster Risk Management and Financing in Africa' (26 November 2018).

18 See ARC, 'Report of the Sixth Session of the Conference of the Parties of the African Risk Capacity Agency' (14-15 March 2018). 
in training and development of technical risk management capacity of African States as well as development of innovative risk financing mechanisms for river floods and tropical cyclones, which are intended to be ready by early $2019 .{ }^{19}$ Economic Communities (RECs)

The AU DRR Strategy designated the RECs as the main implementation mechanisms with the responsibility of providing strategic guidance to their member states through developing and implementing sub-regional DRR/M strategies and coordinating inter-state DRR/M initiatives. ${ }^{20}$ It is thus critical to look at the RECs' DRR/M legal and policy frameworks when analysing ID L frameworks in Africa.

\subsection{Economic Community of West African States (EcoWAS)}

ECOWAs has been the most active REC, adopting a DRM Policy in 2006 based on the African DRR Strategy and its POA 2006-2015. ${ }^{21}$ It has also created several institutional frameworks for DRR/M: the ECOWAS Disaster Management Technical Committee (DMTC); the Ministerial Disaster Management Steering Committee (MDMSC); the Inter-Departmental Coordinating Committee (IDCC); and a Disaster Management Unit (DMU). ${ }^{22}$ In this context, EcowAs adopted a Plan of Action for their Humanitarian Policy covering 2018-2022 in 2018. ${ }^{23}$ The POA captures seven key objectives in the period: enhanced adoption of appropriate legal and policy frameworks for the prevention and response to emergencies; strengthening institutional capacity for preventing and managing humanitarian challenges; enhancing capacity of social actors to prevent and manage humanitarian challenges; developing special measures for the protection of vulnerable populations during humanitarian emergencies; maximising use of media in communicating risk information and enhancing engagement with communities. ${ }^{24}$ ECOWAS also held the Sub-regional DR R Platform in September 2018 in Abidjan, Ivory Coast, that called for firmer political commitment to DRR/M, more effective resource mobilisation and allocation and more

\footnotetext{
19 ARC, Statement on the Tropical Cyclone Idai (26 March 2019).

20 AU/NEPAD, 'Africa Regional Strategy for Disaster Risk Reduction' (July 2004), 15; AU Programme of Action 2006-2015 (n. 7) 5; AU Programme of Action 2015-2030 (n. 7) 11.

21 ECOWAS, 'ECOWAS Policy for Disaster Risk Reduction' (August 2006).

22 Ibid., 18.

23 ECOWAS, 'Plan of Action of the Ecowas Humanitarian Policy 2018-2022' (2018).

24 Ibid., Annex 2.
} 
efficient generation of disaster data and sharing of best practices for effective disaster management. ${ }^{25}$ They specifically insisted on the need for customised hydro-meteorological services so as to improve early warning systems and enhance resilience. ${ }^{26}$ They also called for conducive environment for the exchange of research and scientific expertise, and continuing DRR/M capacity building for member states. ${ }^{27}$

\subsection{The Southern Africa Development Community (SADC)}

SADC has developed DRR/M frameworks to enhance coordinated prevention and response to disasters. It established a DRR Unit to help coordinate preparedness and response and established the Sub-Regional DRR Platform in 2011 as a multi-stakeholder Forum for DRR/M planning and implementation. ${ }^{28}$ It has created a Climate Services Centre that generates and disseminates meteorological, environmental and hydro-meteorological services to enhance early warning and DRR/M planning and decision-making. ${ }^{29} \mathrm{In} 2016$, it adopted the SADC Disaster Preparedness and Response Strategy (2016-2030) to guide $\mathrm{DRR} / \mathrm{M}$ programming in the sub-region and to enhance the integration of $\mathrm{DR} R$, CCA and sustainable development in the planning and policy frameworks of its member states. ${ }^{30}$ It held its latest Sub-Regional DRR Platform on $26-28$ March 2018 in South Africa, which called on all stakeholders to move DRR/M policy formulation to implementation in a coordinated manner; asked for increased commitment in the prioritisation of disaster risk and climate change informed investments for sustainable development in an integrated and inclusive manner; called on member states to increase annual budgetary allocations for $\mathrm{DRR} / \mathrm{M}$ and for international partners to increase financial and technical support for DRR/M; and requested for enhanced disaster monitoring and reporting at the national and sub-regional levels. ${ }^{31}$

25 EcowAS, 'EcowAS Forum urges Modernisation of Hydromet and Disaster Risk Management Services' (23 September 2018).

$26 \quad$ Ibid., para. 5 .

27 Ibid., para. 6.

28 SADC, Disaster Risk Management, para. 7.

29 Ibid., paras. 10-11.

30 'SADC Ministers adopt Regional Disaster Preparedness and Response Strategy' (26 November 2016), available at <https://www.sadc.int/news-events/news/sadc-ministers -adopt-regional-disaster-preparedness-and-response-strategy/>.

31 SADC Conference Outcome Statement, 'Accelerated Collaboration and Partnership for the Implementation of DRR for Sustainable Development in the SADC Region' (28 March 2018). 


\subsection{The Economic Community of Central African States (EccAss)}

ECCASS has responded to disaster concerns by adopting the Central Africa Regional Strategy for Risk Prevention, Disaster Management and Adaptation to Climate Change. ${ }^{32}$ It also set up a Regional Climate Centre to provide better climate services for early warning, planning and decision-making on DRR and CCA for sustainable development. ${ }^{33}$ ECCASs has held several sub-regional DRR Platforms, with the 2018 Platform being delayed until 28 January-2 February 2019 in Burundi. ${ }^{34}$ The Platform noted the main disaster challenges in ECCASS member states as mainly being floods, droughts, thunderstorms, landslides and epidemics. ${ }^{35}$ The Platform was a forum for exchange of ideas and best practices by member states on DRR/M programming, with States showing continued commitment to putting in place effective DRR/M frameworks at the national level. ${ }^{36}$

\subsection{East African Community (EAC)}

The EAC adopted DRR/M Strategy 2012-2016 in 2012 that called for a mind-shift from reactive response to emergencies to a more proactive preventive approach to disasters through vulnerability analysis, risk evaluation and effective early warning systems to build resilience and mitigate disaster impacts on lives, livelihoods and socio-economic infrastructure. ${ }^{37}$ It created a DR R/M Unit at the EAC Secretariat to coordinate DRR/M efforts and a Sub-Regional DRR Platform as a multi-stakeholder forum for DRR/M. ${ }^{38}$ In 2018, it planned to update its DRR/M Strategy and hold its 2nd Sub-Regional DRR Platform, though information is currently unavailable as to whether these milestones were achieved. The EAC Assembly adopted EAC DRR/M Legislation in March 2016 that established the DRR/M Authority and Unit with policy development and implementation mandates respectively. ${ }^{39}$ It also established DRR/M Fund to

32 UNECA, ISDR, AUC and UNDP, 'Assessment Report on Mainstreaming and Implementing Disaster Risk Reduction and Management in Africa' (October 2015) 37.

33 Afri-Alliance, 'Central African Nations to Set Up Regional Climate Centre' (5 October 2016), available at $<\mathrm{https}$ ///afrialliance.org/knowledge-hub/water-and-climate-updates/ central-african-nations-set-regional-climate-centre>.

ACP-EU DRR Programme, 'January 2019: 7th Disaster Risk Reduction Central Africa Platform, available at <https://www.gfdrr.org/en/event/january-20197th-disaster-risk -reduction-central-africa-platform $>$.

Ibid., para. 4.

$36 \quad$ Ibid., para. 6 .

37 EAC, 'Disaster Risk Reduction and Management Strategy 2012-2016' (October 2012) 1.

$38 \quad$ Ibid., $54-56$.

39 EAC Assembly Disaster Risk Reduction and Management Bill 2013, Sections 19-20. 
support prevention and response activities in the sub-region. ${ }^{40}$ Due to limited available information, it is not clear how these legal and institutional frameworks have interacted in 2018 to enhance disaster prevention and response in the sub-region.

\subsection{Inter-Governmental Authority on Development (IGAD)}

IGAD was re-launched as REC in 1996 with a broad mandate of peace and sustainable development, which entails DRR/M. It adopted a new long-term Strategy and 1st Implementation Plan 2016-2020 in 2016.41 A primary objective of IGAD is to help its member states collectively combat drought and other disasters with the aim of building resilience, a critical component of the first Pillar of the Strategy. ${ }^{42}$ IGAD has integrated DRR/M and CCA at strategy and institutional level in the IP 2016-2020 that covers 2018, with the focus being geospatial climate data management; climate monitoring, prediction and early warning; and mainstreaming climate information in key sectors. ${ }^{43}$ As $90 \%$ of disaster risks in its sub-region are climate-related, IGAD has established the IGAD Climate Prediction and Application Centre (ICPAC) charged with the mandate of providing climate information, prediction and timely early warning on disaster risks as well as coordinating all regional activities on climate risk reduction. In 2018, ICPAC, in collaboration with the Meteorological Departments of IGAD member states, continued providing critical climate information and services to enhance early warning and early action in DRR/M through its Greater Horn of Africa Climate Outlook Forums and Bulletins (GHACOF 48, 49 and 50 of 2018). ${ }^{44}$

\section{Disaster Law at the Regional Level in the Middle East and North Africa (MENA) Region}

The MENA region has been classified as a single DRR/M region due to similarities in its disaster profile, hazard risks and prevention/response challenges, with floods, droughts, earthquakes, dust/sandstorms and heatwaves being the

\footnotetext{
$40 \quad$ EAC DRRM Legislation, Sections $25^{-27}$.

41 IGAD Regional Strategy 2015 and Implementation Plan 2016-2020 (January 2016).

42 IGAD Regional Strategy (n. 41) 3, 27, 39-41.

43 IGAD Implementation Plan (n. 41) 6-7.

44 ICPAC, '48th, 49th and 5oth Greater Horn of Africa Climate Outlook Forums', available at $<$ http://www.icpac.net>.
} 
main hazards. ${ }^{45}$ The responsibility for the prevention and response to these hazards has been undertaken by the League of Arab States (LAS), which adopted the Arab Strategy for DRR 2020 (ASDRR-2020) in December 2010. ${ }^{46}$ ASDRR-2020 was reviewed in 2018 with the global adoption of the Sendai Framework and the SDGs, resulting in the adoption of the Arab Strategy for DRR 2030 (ASDRR-2030) in April 2018. ${ }^{47}$ Its vision is the protection of existing developmental gains and enhancing success of future sustainable development efforts through integrating and mainstreaming DRR and CCA in national and regional development plans and strategies. ${ }^{48}$ This is to be achieved through the reduction of disaster losses as per the Sendai Framework. ${ }^{49}$ ASDRR-2030 has four priority areas: enhanced understanding of disaster risks through research and data analysis; strengthening disaster governance through enhanced and integrated legal, policy and institutional frameworks; increasing access to resources for DRR/M for multi-sectoral resilience; and effective contingency planning and preparedness for effective disaster response, recovery and rehabilitation. ${ }^{50}$ In availing resources to achieve these goals, ASDRR-2030 requires Arab States to dedicate $1 \%$ of their national development funding and development assistance to $\mathrm{DRR} / \mathrm{M}$ as well as seek financial support from regional financing mechanisms. ${ }^{51}$ Institutional support for the implementation of ASDRR-2030 is to be provided by the LAs Secretariat, with UN Specialised Agencies, regional commissions, national authorities and the civil society providing support. ${ }^{52}$

ASDRR-2030 is to be implemented through three detailed Plans of Action covering three phases: 2018-2020, 2021-2025 and 2026-2030.53 The first Prioritised Plan of Action 2018-2020 (PPA 2018-2020) was adopted during the 4th Arab Conference on DRR, which was part of the joint Arab-Africa DRR Platform

45 Mihir Bhat, 'India and the Middle East: Common Area of Action on the Sendai Framework' (12 June 2018), available at <https://www.mei.edu/publications/india-and-middleeast-common-areas-action-sendai-framework>, para. 2; John Calabrese, 'Responding to Natural Disasters: Rowing against a Fast-rising Tide of Risk' (26 May 2016), available at $<$ https://www.mei.edu/publications/responding-natural-disasters-rowing-against-fastrising-tide-risk $>$, paras. 10-24.

46 League of Arab States, 'The Arab Strategy for Disaster Risk Reduction 2020', available at <https://www.unisdr.org/files/18903_17934asdrrfinalenglishjanuary20111.pdf>, 3-4.

47 League of Arab States, 'The Arab Strategy for Disaster Risk Reduction 2030', available at <https://www.preventionweb.net/files/59464_asdrrreportinsidefinalforweb.pdf>, 4-5.

$48 \quad$ Ibid., 16.

$49 \quad$ Ibid., 16.

50 Ibid., 18-22.

$5^{1} \quad$ Ibid., 23-24.

52 Ibid., 24-25.

53 Ibid., 11. 
held in Tunis in October 2018. ${ }^{54}$ The focus of PPA 2018-2020 is: improved multihazard qualitative and quantitative disaster risk assessment; strengthened multi-stakeholder cooperation for DRR/M, especially through the biennial DRR Conferences; increased multi-media information sharing and knowledge building for better resilience; enhanced gender-sensitive and gender responsive DRR/M; and increased capacity for early warning and early action in DRR/M. ${ }^{55}$ Implementation monitoring for ASDRR-2030 and PPA 2018-2020 is undertaken by the LAS Secretariat and ISDR at the national and regional level using the Sendai Monitor. ${ }^{56}$

Further, in enhancing multi-sectoral all-society approaches to DRR/M, LAS and ISDR established the Arab Partnership for DRR, with its first meeting in April 2018. ${ }^{57}$ The meeting agreed on the need for a dedicated evidence-based report (Arab Regional Assessment Report) detailing the nature and character of hazards in the region, the $\mathrm{DRR} / \mathrm{M}$ measures in place to enhance disaster resilience in the region, and to identify the way forward in managing existing risks and preventing new ones to enhance sustainable development. ${ }^{58}$ The Report is to be developed through a multi-stakeholder process and will form the basis of discussions in the subsequent Arab Regional DRR Platform. Relief operations in 2018 continued to be guided by the Doha Declaration on Strengthening Disaster Law Frameworks in the MENA region adopted in December 2016.

The Need for Action in the Implementation of IDL in Africa and MENA Regions

African and Arabian States have made substantive efforts to improve the legal and institutional framework for DRR/M in their regions. Though this is commendable, it is important to focus more on the active implementation of these frameworks to enhance multi-hazard resilience and ensure effective prevention, preparedness, response, recovery and rehabilitation. This is especially so as hazard occurrences are increasing in frequency and intensity in these regions due to climate change, while the communities remain vulnerable due to poverty, inequality and limited access to alternative forms of livelihoods. The

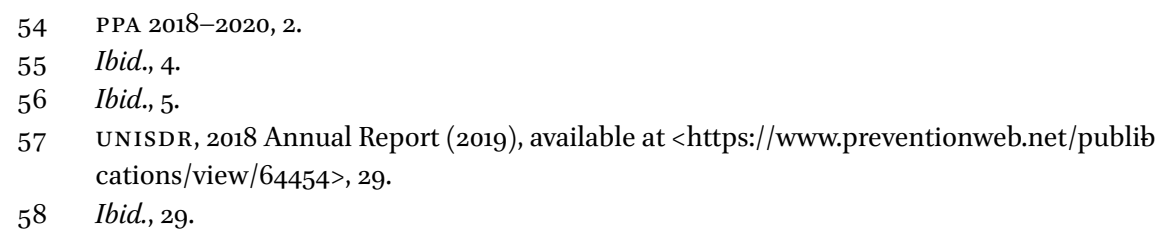


need for IDL to progress from precepts to practice in the two regions were affirmed by AU Commissioner Ambassador Josefa Sacko - and echoed by the Special Representative of the UNSG on DRR Ms. Mami Mizutori - as follows "We have a lot of papers on our shelves but need to pass to action".59

$59 \quad$ Ibid., iv. 